\title{
COMPUTED TOMOGRAPHY ASSESSMENT OF CANAL CENTERING ABILITY USING HAND AND ROTARY INSTRUMENTS - AN IN VITRO STUDY
}

\author{
Alka Arora ${ }^{1}$, Devendera Chaudhary ${ }^{2}$, Shalu Krishan ${ }^{3}$, Bhupinder Kaur Padda ${ }^{4}$ \\ ${ }^{1}$ Sr. Lecturer, Deptt. of Conservative Dentistry \& Endodontics, Maharaja Ganga Singh Dental College \& Research Centre, Rajasthan, India \\ ${ }^{2}$ Prof \& HOD, Deptt. of Conservative Dentistry \& Endodontics, Maharaja Ganga Singh Dental College \& Research Centre, Rajasthan, India \\ ${ }^{3}$ Prof \& HOD, Deptt. of Conservative Dentistry \& Endodontics, National Dental College, Punjab, India \\ ${ }^{4}$ Prof \& HOD, Deptt. of Conservative Dentistry \&Endodontics, Hazaribag College of Dental Sciences and Hospital, Jharkhand, India
}

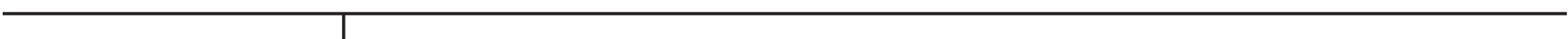

ABSTRACT

Aim: The present in vitro study aims to evaluate canal preparation comparing centering ability of ProTaper, Mtwo, Wave One, Hand Ni-Ti K-files using Computed Tomography(CT). Materials and Methods: Sixty extracted permanent teeth were selected and decoronated at $11 \mathrm{~mm}$ from the apical end. Samples were randomly divided into 4 groups as ProTaper, Mtwo, Wave One, Hand Ni-Ti K-files. Teeth were scanned by CT Scanner. Sectioning was started at $1 \mathrm{~mm}$ from the apex up to coronal orifice. Nine levels at $1 \mathrm{~mm}$ each were chosen for evaluation in the Computed Tomography. The canals were prepared and a post instrumentation scan was again taken. The pre and postoperative CT images were superimposed at all nine levels. The canal centering ability was calculated. Statistical data was evaluated using One Way Analysis Of Variance test. Results: Amongst the rotary and reciprocal groups the best canal centering ability at the apical third was seen with Wave one. All the three groups behaved similarly in the middle and coronal thirds of the root canal. Conclusion: Keeping in mind the importance of apical third preparation and consistent behaviour in all directions, Wave One may be considered by far the best in the apical third.
\end{abstract}

Keywords: Canal centering, Computed Tomography, Hand Ni Ti K files, Mtwo, Wave One

\section{INTRODUCTION}

A major cause of endodontic failure is the inability to locate, debride or obturate properly all portals of the root canal system. Inaccurate shaping procedures can produce aberrations such as zips, elbows, danger zones, perforations, ledges which compromise the integrity of the root itself with dentin removal from the canal walls leading to difficulties in obturation. ${ }^{1}$ Goal of instrumentation is to produce a continuously tapered preparation that maintains the canal anatomy, keeping the foramen as small as possible without any deviation from the original canal curvature. ${ }^{2}$ It relates to the ability of the instrument/ instrument techniques to uniformly prepare all the surfaces of the canal, thus enabling the central axis of the prepared canal coincide with that of the original canal, especially relevant in the canals with curvatures. ${ }^{3}$

Nickel-titanium engine-driven rotary instruments are used increasingly in endodontic practice. Due to their flexibility, coupled with the design of the blades, it is feasible to use nickel titanium instruments with a hand piece in a rotary motion to prepare root canals. ${ }^{4}$ While hand instruments continue to be used, NiTi rotary instruments and advanced preparation techniques offer new perspectives for root canal preparation that have the potential to avoid some of the major drawbacks of traditional instruments. $^{5}$ 
In the past, methods such as scanning electron microscope, radiographic evaluation, photographic assessment and computer manipulation for comparative analysis were used for assessment of canal instrumentation. The above mentioned methods are invasive in nature, accurate repositioning of pre and post instrumented specimen is difficult, they are labor intensive, and there is a disadvantage of loss of specimen. Recently a new technology computed tomography has been developed which can render cross-sectional and 3D images that are highly accurate and quantifiable. ${ }^{6}$ It is possible to scan teeth before and after instrumentation, and then compare the before and after images of canal systems. ${ }^{1}$

Nowadays, market is flooded with so many different root canal preparation systems. Therefore there is a need to check which system is the one which gives an ideal preparation and dentin overcutting is avoided. In this study we have compared and evaluated the centering ability of Protaper, Mtwo, Wave One and Hand Ni-Ti K-files root canal preparation systems.

\section{MATERIALS AND METHODS:}

Sixty freshly extracted permanent teeth having single, straight and well developed roots were selected. Intra Oral Periapical Radiographs were taken of all the samples from buccolingual and mesiodistal aspects to verify the round shape and type I configuration of the canal. If the difference between buccolingual \& mesiodistal measurements of the canal was more than $1 \mathrm{~mm}$, the sample was considered to be oval and discarded. The specimens were decoronated with carborundom discs at $11 \mathrm{~mm}$ from the apical end of root and divided into 4 experimental groups as follows:-

$\begin{array}{lll}\text { GROUP-A } & : & \text { Protaper rotary files } \\ \text { GROUP-B } & : & \text { Mtwo rotary files } \\ \text { GROUP-C } & : & \text { WaveOne files } \\ \text { GROUP-D } & : & \text { Hand Ni-Ti K- files }\end{array}$

The teeth were embedded in dental stone and scanned by Light Speed Plus CT Scanner as shown in
Figure1 Sectioning was started at $1 \mathrm{~mm}$ from the apex up to coronal orifice. The CT scans were done at $140 \mathrm{KV}$ and $130 \mathrm{~mA}, 1-\mathrm{mm}$-thick axial sections, and beam incidence at the central portion on the device used to fix the specimens.

Nine levels at $1 \mathrm{~mm}$ each were chosen for evaluation in the CT. Images were stored in the computer's hard disk for further comparison between pre and post instrumentation data by using DiCom software. After the pre-instrumention scan, scanned teeth were prepared as follows:

Group A: Protaper NiTi rotary systems: Canals were prepared using torque control endodontic hand piece $\mathrm{X}$ smart using NiTi protaper rotary files after ascertaining the working length upto F3 ( Finishing file).

Group B: Mtwo NiTi rotary system: Samples in this group were prepared using $\mathrm{M}$ two rotary files upto size $30 / .05$ taper.

Group C: WaveOne files: Samples were prepared upto primary file having tip size ISO 25 and $8 \%$ taper in reciprocating motion.

Group D: Hand Ni-Ti K files: Samples in this groups were prepared with crown down technique after ascertaining the working length upto 30 no. K file.

The root canal was irrigated using saline $2 \mathrm{ml}$ per canal instrumentation and a total $5 \mathrm{ml}$ of $3 \%$ sodium hypochlorite $(\mathrm{NaOCl})$ per canal. Glyde (Dentsply Maillefer) lubricant was used throughout the canal procedure. A post instrumentation scan was again taken after preparation of the canals. The pre and postoperative CT images were superimposed for each group at all nine levels and canal circumferences were traced using the software Paint Shop Pro 9. The canal centre was determined by pixel measurement. The images were superimposed using the canal centre as reference. This centering ratio was calculated for all the four groups at each level using the following formula given by Gambill et al:

$$
(\mathrm{A} 1 \text { - A2) / (B1 - B2 ) Or (B1 - B2) / A1 - A2) }
$$


If these numbers are not equal, the lower figure is considered the numerator of the ratio. According to this formula, a result of ' 1 ' indicates perfect centering. If the value was closer to 1 , then it indicates the instrument is more centered in the root canal.

A1 is the distance from the mesial edge of the root to the mesial edge of the uninstrumented canal. B1 is the distance from distal edge of the root to the distal edge of the uninstrumented canal. A2 is the distance from the mesial edge of the root to the mesial edge of the instrumented canal. B2 is the distance from distal edge of the root to the distal edge of the instrumented canal (Figure 1,2).

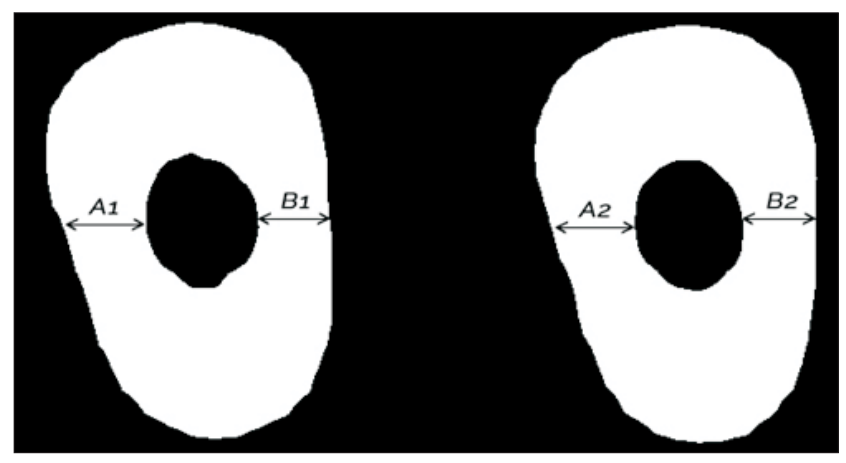

Figure 1. Preoperative C.T Scan image Postoperative C.T Scan Image

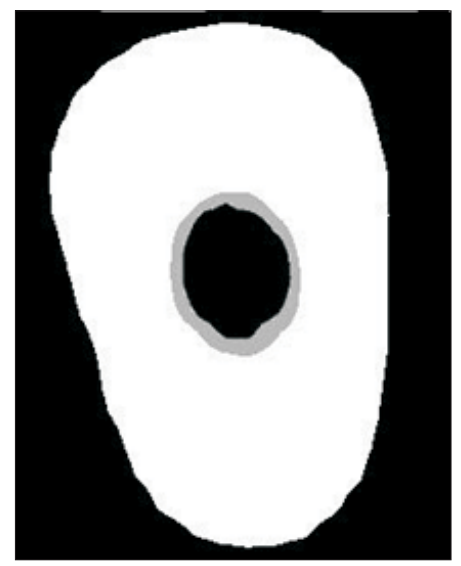

Figure 2. Superimposition of pre and post operative CT images (gray colored area shows the superimposed part)

\section{RESULTS:}

The best centering ratio was depicted by Group B in coronal third and least centring ratio by group $\mathrm{C}$ had least centering ratio.( Table 1) In middle third, Group A had better centering ratio than the rest of the groups. In apical third in the group $\mathrm{C}$ depicted the highest values. The minimum values in the mesiodistal aspect of apical one third were seen in group D .Thus apical one third showed the best centering ratio in group $\mathrm{C}$ as shown graphically in Graph 1.

Table 1: The maximum and miniumum centering ratio in four groups

\begin{tabular}{|l|l|l|}
\hline & \multicolumn{2}{|c|}{ CENTERING RATIOS } \\
\hline & MAXIMUM & MINIMUM \\
\hline Coronal third & Group B -0.73 & GroupC - 0.68 \\
\hline Middle third & Group A -0.77 & Group D- 0.66 \\
\hline Apical third & Group C- 0.94. & Group D-0.73 \\
\hline
\end{tabular}

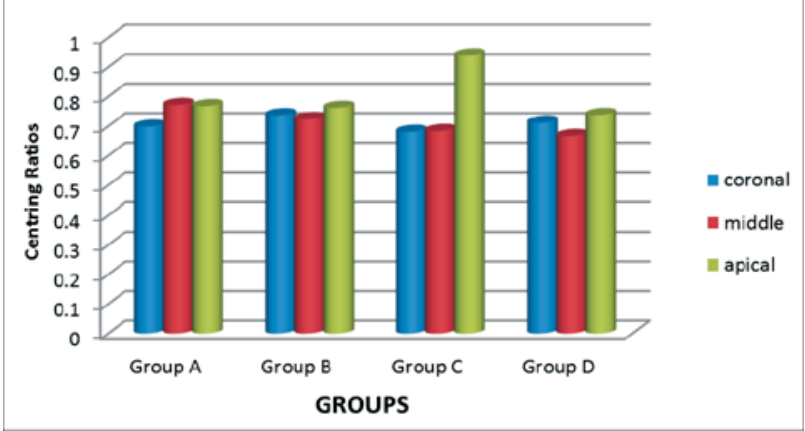

Graph 1. Comparison of centering ratios in all four groups

Statistically significant difference was observed when canal centering ratio of apical third of Group $\mathrm{C}$ was

Table 2. One way ANOVA comparing the centering ratios

\begin{tabular}{|l|l|r|r|r|r|r|}
\hline & & $\begin{array}{c}\text { Sum of } \\
\text { Squares }\end{array}$ & df & $\begin{array}{c}\text { Mean } \\
\text { Square }\end{array}$ & F & $\begin{array}{c}\text { Signif- } \\
\text { icance }\end{array}$ \\
\hline \multirow{5}{*}{ CORONAL } & $\begin{array}{l}\text { Between } \\
\text { Groups }\end{array}$ & 0.025 & 3 & .008 & .574 & .635 \\
\cline { 2 - 7 } & $\begin{array}{l}\text { Within } \\
\text { Groups }\end{array}$ & 0.814 & 56 & .015 & & \\
\cline { 2 - 7 } MIDDLE & Total & 0.839 & 59 & & & \\
\hline \multirow{5}{*}{ APICAL } & $\begin{array}{l}\text { Between } \\
\text { Groups }\end{array}$ & 0.098 & 3 & .033 & 2.097 & .111 \\
\cline { 2 - 7 } & $\begin{array}{l}\text { Within } \\
\text { Groups }\end{array}$ & 0.868 & 56 & .016 & & \\
\cline { 2 - 7 } & Total & 0.966 & 59 & & & \\
\hline & $\begin{array}{l}\text { Between } \\
\text { Groups }\end{array}$ & 0.387 & 3 & .129 & 9.298 & $<.001 * *$ \\
\cline { 2 - 7 } & $\begin{array}{l}\text { Within } \\
\text { Groups }\end{array}$ & 0.777 & 56 & .014 & & \\
\cline { 2 - 7 } & Total & 1.164 & 59 & & & \\
\hline
\end{tabular}


Schilder recognized that canal shaping should be performed with respect to unique anatomy of each root and in relation to the technique of root canal filling. He outlined several mechanical objectives for optimal instrumentation i.e the root canal preparation should maintain the path of the original canal, the apical foramen should remain in its original position and the apical opening should be kept as small as practical. ${ }^{8}$ These objectives of an ideal root canal preparation can be difficult to achieve by using stiff stainless steel hand instrumentation. ${ }^{3,9,10,11}$ Thus, the introduction of rotary nickel titanium (NiTi) instrumentation was an important step in optimal root canal shaping. In this study an attempt has been made to do so by comparing Hand NiTi K-file to Protaper, M two and Wave One systems by judging their effectiveness in canal preparation by assessing centering ability.

Sixty teeth with straight and roughly round canals were selected so that it was easier to standardise the parameter taken for the study. Generally the length of the crown varies more than the root which might make the straight line access difficult. Hence, decoronation of teeth was done to give a straight line access. The teeth were embedded in dental stone so that the pre and postoperative sections of CT scan could be easily be superimposed on each other without any change in the angulation. The slicing for C.T was started from at 1 $\mathrm{mm}$ from the apex up to coronal orifice. Nine levels at 1 $\mathrm{mm}$ each were chosen for evaluation in the CT which were divided into three parts comprising three sections each i.e coronal section 1,2,3, middle section 4,5,6 and apical section 7,8,9 respectively .

Centering ability was calculated according to Gambill's equation which states that "the mean centering ratio indicates ability of the instrument to stay centered in the canal. ${ }^{12}$ If the value was 1 then it indicated perfect centering. If the value is less than 1 , it indicated that some portion of the canal had remained untouched by the root canal instrument or that the canal had been under prepared from that particular side. If the value was 0 , it indicated that no cutting took place.
The best centering ability was noted in WaveOne group which although seen in apical thirds had the most significant results. The centering ability of WaveOne can be best explained by the reciprocating motion, the variable section design, the $\mathrm{M}$ wire the reverse cutting blades, or a combination of these variables.

Berutti et al also found that the new Wave One NiTi Primary reciprocating single-file better maintained the original canal anatomy, with less modification of the canal curvature compared with the ProTaper system upto F2. ${ }^{13}$ In another study also WaveOne and Reciproc instruments obtained better centering ability at all levels especially at the end point of preparation when compared with Protaper and Mtwo instruments. ${ }^{14}$ In a study conducted by Maitin et al centering ability of Protaper was considered least i.e. the transportation of canals was maximum with Protaper. However in our study the centering ability was best for protaper in middle third. Moreover author claims that the Mtwo files show better centering in coronal and middle thirds. However this is a slight departure from our results as we see Mtwo with best centering only in coronal thirds. Although our studies concur in the results of Mtwo at apical thirds. The difference of result can be attributed to the difference in the teeth selection of our study as we did not take curved canals in consideration. ${ }^{15}$ Results of this study are also in concurrence with study conducted by Goldberg etal who reported that WaveOne instrument had excellent centering ability with a low risk of fracture or blockage and a short shaping time, regardless of the operator's level of experience. ${ }^{16}$

Comparing the instrumentation evaluated in this study, amongst the rotary and reciprocal groups the best canal centering ability at the apical third was seen with WaveOne stating that reciprocating motion promoted better centring ability in apical third.

\section{CONCLUSION:}

Keeping in mind the importance of apical third preparation and consistent behaviour in all directions, WaveOne can be considered the best in the apical third of the root canal. 


\section{REFERENCES:}

1. Gandhi A, Gandhi T. Comparison of canal transportation and centering ability of hand Protaper files and rotary Protaper files by using micro computed tomography. RSBO 2011; 8(4):375-380

2. Hulsmann M, Peters O. Mechanical preparation of root canals: shaping goals, techniques and means. Endodontic Topics 2005;10(1):30-76

3. Kandaswamy D, Venkateshbabu N. Canal-centering ability: An endodontic challenge. J.Conserv Dent 2009; 12 (1):3-9

4. S Necchi, S. Taschieri, L. Petrinil \& F. Migliavacca. Mechanical behaviour of nickel-titanium rotary endodontic instruments in simulated clinical conditions: a computational study . Int Endod J 2008; 41 (11):939-949.

5. Merh A,Singhbal B, Parekh V,Mehta S. To Comparatively Evaluate the Canal Centering Ability of the ENDO EZE AET System and Wave One System in Simulated Canals.Natl J Med Dent Res 2014;2(2) : 32-41

6. Nagaraja S, Murthy B. CT evaluation of canal preparation using rotary and hand NI-TI instruments: An in vitro study. J Conserv Dent Jan-Mar 2010;13(1):16-22

7. Stern S, Patel S, Foschi F, Sherriff M, Mannocci F. Changes in centring and shaping ability using three nickel-titanium instrumentation techniques analysed by micro-computed tomography. Int Endod J 2012;45:514-23

8. GR Young. The principles of techniques for cleaning root canals. Aust Dent J 2007;52:(1Supl):S52-S63

9. Garip Y, Günday M. The use of computed tomography when comparing nickel-titanium and stainless steel files during preparation of simulated curved canals. Int End J 2001 ; 34(6) $452-457$
10. Miranzi.BAS, Apical and cervical displacement produced by hand and engine-driven stainless steel and nickel-titanium instruments in simulated curved root canal..Braz J Oral Sci 2011; 10(2):136-139

11. Walton RE. Histologic evaluation of different methods of enlarging the pulpcanal space. J Endod 1976;2(10):304-11

12. Gambill J. Alder M, Rio C E D. Comparison of NickelTitanium and Stainless Steel Hand-File Instrumentation Using Computed Tomography. J Endod 1996 ;22( 7):369- 75

13. Berutti E, Paolino D. Root Canal Anatomy Preservation of WaveOne Reciprocating Files with or without Glide Path. J Endod 2012;38(1):101-104

14. Mahdi J, Maruish R. Centering ability and canal transportation of :ProTaper,Mtwo, WaveOne,Reciproc in simulated curved canals (A comparative study). MDJ 2013;10(2): 147-55

15. Maitin N,ArunagiriD, Dexter B.Maitin S N,Kaushik S. An ex vivo comparative analysis on shaping ability of four NiTi rotary endodontic instruments using spiral computed tomography.J Conserv Dent 2013;16(3)

16. Goldberg M,Dahan S, Machtou P. Centering Ability and Influence of ExperienceWhen Using WaveOne Single-File Technique in Simulated Canals. Int J Dent 2012 (1-8)

\section{Source of Support: Nil, Conflict of Interest: None Declared}

